\title{
Editorial
}

\section{Know and Care Life Friends -Microbiota}

\author{
DOI: http://dx.doi.org/10.3329/kyamcj.v9i3.38779
}

The almost all parts of human body inhabit trillions of different microorganisms with harmony-surprisingly out number human cells by 10 to 1 . As their small size, however, microorganisms make up only about 1 to 3 percent of the body's mass (in a 200-pound adult, that's 2 to 6 pounds of bacteria), but perform vital functions including digestion of essential nutrients, maturation of intestinal physiology, development and stimulation of immune system, systemic effects on blood lipids and the inhibition of harmful bacteria essential for survival of human being. ${ }^{1,2}$

So much human coexisting microorganisms are known as microbiota or normal flora whichis a highly complex community of microbe sincluding bacteria, viruses, fungi, protozoa and archaea. Scientifically they are of two types, one is responsible for ailment minor group (3-5\%) and another is functioning friendly helpful activities major group (95$97 \%)$. Their composition and action vary according to their site of locations, ages, sexes, races, diets and geographic habitation of the hosts. ${ }^{3}$

Currently the friendly microbiota has been all but ignored as determinants of health and disease due to lack of proper current knowledge. This article on above mentioned topic is a sincere attempt to focus friendly microbiota on the basis of scientific evidence for greater interest to obtain maximum benefit out of them. ${ }^{4,5}$

Knowledge about microorganism was quite different 150 years ago when it was discovery in 1673 . Then it was hard to believe that microbe could cause human ailment before discovery of germ theory of disease, proving that specific diseases were caused by specific pathogenic micro organisms by Louis Pasteur and Robert Koch in the late 1870s .5 The first scientific evidence of microorganisms in normal human system was observed by Austrian pediatrician Theodor Escherichin the intestinal flora of healthy children and later named Escherichia coli. ${ }^{6}$ The idea of microorganisms' disease producing frightening ability was changed on observing the unbelievable helping functionsin 1900 through research on intestinal microbe by Dr. Metchnikoff, in 2001 the Nobel laureate-microbiologist Joshua Lederberg termed microbiome to those microorganisms found in normal human body. ${ }^{8}$

Humans are born sterile and microbial colonization begins immediately at birth. It is estimated that 10 times of human cells i.e. 100 trillion microbiota occupies some specific sites of the body. But they are found in significant number in five major organs like oral cavity, oropharynx, nostrils, gastrointestinal tract, vagina and on skin. It is estimated that the most heavily colonized organ is the gastrointestinal tract containing over $70 \%$ of all the microbes in the human body. ${ }^{1,2}$
The human gut has a calculated surface area of a tennis court $\left(200 \mathrm{~m}^{2}\right),{ }^{9}$ and, as such a large organ, represents a major surface for highest microbial colonization. Additionally, the gut is rich in nutrients that are used by microbes, making it a preferred organ for their habitation. As much of this is in our gastrointestinal tract, which represents $\sim 10 \%$ of our mass, which hosts up to 1000 bacterial species that encode about 5 million genes. Surprisingly they perform many of the functions required for our physiology and survival. Consequently, it is also established to some scientist as "forgotten organ,"10 observed as a "virtual endocrine organ" and considered to be an "essential organ."11

Significant inter-individual variability in the gut microbiota composition found to healthy adults which suggest physiological role in the maintenance of health status. Now it is proved that human don't have all enzymes to digest all diet, microbe break down many of the proteins, lipids and carbohydrates in our diet into nutrients for absorption. Moreover, gut microbiota produces beneficial compounds, like vitamins, anti-inflammatories and perform fat storage, angiogenesis regulation, control mood etc. These functions are not performed by our own genome..$^{12,13}$

Interestingly, genes encoded by the human gut microbiota encode proteins required for host survival, but not present in the human genome. This finding has led to the definition of the gut microbe as "our forgotten organ". ${ }^{14}$

Microbiologist has led exciting discoveries on microbial direct action on the gut mucosa and the enteric nervous system (ENS). The metabolic output of the gut microbiota gives it a reach well beyond the local intestinal compartment. Thus, considering the ability to influence the function of distal organs and systems, in many respects, the gut microbiota resembles an endocrine organ which produce numerous chemicals of a hormonal nature like gamma-aminobutyric acid (GABA), noradrenaline, dopamine, and serotonin, released into the bloodstream and act at distal sites. The targets for these substances are not just the local ENS but many other organs including the brain. It releases its hormonal products into interstitial tissue to be picked up by blood and lymph capillaries, and these secretions are usually effective in low concentrations on target organs or tissues remote from the enteric microbiota. Moreover, specific members of the overall microbial community can respond to hormones secreted by the host. ${ }^{15,16}$ Brain like function of gut microbiota in humans is the most compelling evidence of a gut microbe-brain interaction came to light more than 26 years ago from the finding of a dramatic improvement in patients with hepatic encephalopathy, after the administration of oral Rifaximinantibiotics. ${ }^{17}$ 
suggested a crucial role of the human microbiota on human health and disease ${ }^{18,19}$ via several mechanisms. First, the microbiota has the potential to increase energy extraction from food,$^{20}$ increase nutrient harvest,,$^{19,20}$ and alter appetite signaling ${ }^{21}$. The microbiota contains approximately 150 times more. ${ }^{20}$ genes than are found in the entire human genome 22 and provides humans with specific enzymes and biochemical pathways. ${ }^{19}$ For these reasons gut microbiota, has even been considered to be an "essential organ". ${ }^{23}$

To take care of human microbiota known as forgotten/ endocrine/ essential organ utmost importance to be given in the following actions-24

encourage normal vaginal delivery for microbial colonization from mother Promote breast-feeding for establishment of microbiota during infancy, advice minimal use of antibiotics for minor infections in kids as it disrupts normal flora and predispose to disease of opportunistic infection and childhood obesity. avoid unnecessary use of chemical disinfectants which can make bacteria resistant to treatment, and promote of outdoor play that allows exposure to microbe through dirt which help to develop immunity against cancer/leukemia in children.

\section{References}

1. Ley RE, Peterson DA, Gordon JI. Ecological and evolutionary forces shaping microbial diversity in the human intestine Cell. 2006;124:837-848.

2. Whitman WB, Coleman DC, Wiebe WJ. Prokaryotes: the unseen majority. Proc Natl Acad Sci, USA. 1998;95:65786583

3. Hollister EB, Gao C, Versalovic J. Compositional and functional features of the gastrointestinal microbiome and their effects on human health.Gastroentero. 2014; 146(6):1449-1458

4. Kunz C, Kuntz S , Rudloff S. Intestinal flora. Adv Exp Med Biol. 2009;639:67-79.

5. Morelli L. Postnatal development of intestinal microflora as influenced by infant nutrition. J Nutr. 2008;138:S1791S1795.

6. Kara R, Human microbiome, Encyclopedia Britannica.

7. Gordon R. The alarming history of medicine. New York: S, Martin's Press. 1993;164.

8. Bonamichi-Santos R, Aun MV, Agondi RC, Kalil J, Giavina-Bianchi P. Microbiome and asthma: what have experimental models already taught us? J Immunol Res. $2015 ; 6147-6158$
9. Gebbers JO, Laissue JA. Immunologic structures and functions of the gut.Schweiz Arch Tierheilkd. 1989;131: 221-238,

$10 \mathrm{~V}$. D'Argenio, V. Salvatore F. The role of the gut microbiome in the healthy adult status. Clinica Chimica Acta. 2015;451:97-102

11 Wang B. The Human Microbiota in Health and Disease Engineering. 2017;3:71-82

12. Clarke Endocrine Function of the Gut Microbiota Mol Endocrinol. 2014;28(8):1221-1238

13. Flint HJ, Scott KP, Duncan SH, Louis P, Forano E. Microbial degradation of complex carbohydrates in the gut. Gut Microbes. 2012;3:289-306.

14. Qin J, Li R, Raes J, A human gut microbial gene catalogue established by metagenomic sequencing. Nature. 2010;464:59-65.

15. O'Hara AM, Shanahan F. The gut flora as a forgotten organ. EMBO Rep. 2006;7:688-693.

16. Forsythe P, Sudo N, Dinan T, Taylor VH, Bienenstock J. Mood and gut feelings. Brain Behav Immun. 2010; 24:9-16.

17.Evans JM, Morris LS, Marchesi JR. The gut microbiome: the role of a virtual organ in the endocrinology of the host. J Endocrinol. 2013;218:R37-R47.

18. Freestone PP, Sandrini SM, Haigh RD, Lyte M. Microbial endocrinology: how stress influences susceptibility to infection. Trends Microbiol. 2008;16:55-64.

19 Morgan MY. The treatment of chronic hepatic encephalopathy. Hepato gastroenterol. 1991;38:377-387.

20. Ley RE, Turnbaugh PJ, Klein S, Gordon JI. Microbial ecology: human gut microbes associated with obesity. Nature. 2006;444(7122):1022-10223.

21. Gill SR, Pop M, Deboy RT, Eckburg PB, Turnbaugh PJ, Samuel BS. Metagenomic analysis of the human distal gut microbiome. Science. 2006;312 5778:1355-1359.

22. Turnbaugh PJ, Ley RE, Mahowald MA, Magrini V, Mardis ER, Gordon JI. Anobesity-associated gut microbiome with increased capacity for energy harvest. Nature. 2006;444 (7122):1027-1031. 
23. Perry RJ, Peng L, Barry NA, Cline GW, Zhang D. Acetatemediates a microbiome-brain-?-cell axis to promote metabolic syndrome Nature. 2016;534(7606): $213-217$.
24. Ursell LK, Haiser HJ, Van Treuren W, Garg N, Reddivari $\mathrm{L}$,Vanamala $\mathrm{J}$, et al. The intestinal metabolome: an intersection between microbiota and host. Gastroenterology. 2014;146(6):1470-1476.

\section{Dr. Abdullah Akhtar Ahmed}

Professor of Microbiology

KhwajaYunus Ali Medical College 